\title{
Particle tracking analysis of river-aquifer interaction via bank infiltration techniques
}

\begin{abstract}
Induced bank infiltration (BI) is commonly implemented in other countries, but remains new and unexplored in Malaysia. Increasing river pollution could affect drinking water resources. Given the threat of pollution to raw water sources, applying induced BI to sustain water management is essential. This paper presents a case study of the BI method, which evaluates the effects of groundwater pumping and BI operation on the installation of wells as well as determines the effect of pumping rate on flow paths, travel time, the size of the pumping and capture zone delineation, and groundwater mixing in a pumping well in Jenderam Hilir, Malaysia. The proposed method performs infiltration safely and achieves the ideal pumping rate. Numerical modeling packages, MODFLOW and MODPATH (particle tracking) were used. Results indicate that the migration of river water into the aquifer is generally slow and depends on the pumping rate and distance from well to the river. Most water arrives at the well by the end of a pumping period of 1-5 days at 3,072 $\mathrm{m} 3 /$ day for test wells DW1 and DW2, and during simultaneous pumping for DW2 and PW1 for a well located 36 and $18 \mathrm{~m}$, respectively, from the river. During the 9.7-day pumping period, $33 \%$ of the water pumped from the DW1 well was river water, and $38 \%$ from DW2 throughout 4.6 days was river water. The models provide necessary information for water operators in the design and construction of pumping and sampling schedules of BI practices.
\end{abstract}

Keyword: Bank infiltration; Particle tracking; Groundwater; Modeling; MODFLOW; MODPATH Int 